\title{
Impact of plant sterols enrichment dose on gut microbiota from lean and obese subjects using TIM-2 in vitro fermentation model
}

Citation for published version (APA):

Cuevas-Tena, M., Alegria, A., Jesus Lagarda, M., \& Venema, K. (2019). Impact of plant sterols enrichment dose on gut microbiota from lean and obese subjects using TIM-2 in vitro fermentation model. Journal of Functional Foods, 54, 164-174. https://doi.org/10.1016/j.jff.2019.01.005

Document status and date:

Published: 01/03/2019

DOI:

10.1016/j.jff.2019.01.005

Document Version:

Publisher's PDF, also known as Version of record

Document license:

Taverne

Please check the document version of this publication:

- A submitted manuscript is the version of the article upon submission and before peer-review. There can be important differences between the submitted version and the official published version of record.

People interested in the research are advised to contact the author for the final version of the publication, or visit the DOI to the publisher's website.

- The final author version and the galley proof are versions of the publication after peer review.

- The final published version features the final layout of the paper including the volume, issue and page numbers.

Link to publication

\footnotetext{
General rights rights.

- You may freely distribute the URL identifying the publication in the public portal. please follow below link for the End User Agreement:

www.umlib.nl/taverne-license

Take down policy

If you believe that this document breaches copyright please contact us at:

repository@maastrichtuniversity.nl

providing details and we will investigate your claim.
}

Copyright and moral rights for the publications made accessible in the public portal are retained by the authors and/or other copyright owners and it is a condition of accessing publications that users recognise and abide by the legal requirements associated with these

- Users may download and print one copy of any publication from the public portal for the purpose of private study or research.

- You may not further distribute the material or use it for any profit-making activity or commercial gain

If the publication is distributed under the terms of Article $25 \mathrm{fa}$ of the Dutch Copyright Act, indicated by the "Taverne" license above, 


\title{
Impact of plant sterols enrichment dose on gut microbiota from lean and obese subjects using TIM-2 in vitro fermentation model
}

\author{
María Cuevas-Tena ${ }^{\mathrm{a}}$, Amparo Alegria ${ }^{\mathrm{a}, *}$, María Jesús Lagarda ${ }^{\mathrm{a}}$, Koen Venema ${ }^{\mathrm{b}}$ \\ ${ }^{a}$ Nutrition and Food Science Area, Faculty of Pharmacy, University of Valencia, Avd Vicent Andrés Estellés s/n, 46100 Burjassot, Valencia, Spain \\ ${ }^{\mathrm{b}}$ Centre for Healthy Eating \& Food Innovation, Maastricht University - Campus Venlo, St. Jansweg 20, 5928 RC Venlo, the Netherlands
}

\section{A R T I C L E I N F O}

\section{Keywords:}

Plant sterols

Gut microbiota

TIM-2 in vitro model

Fecal sterols

Short chain fatty acids

\begin{abstract}
A B S T R A C T
There are scarce data on plant sterols (PS) and gut microbiota relationship. The purpose of this study is to compare the interaction between PS and gut microbiota through in vitro colonic fermentation studies using a validated system (TIM-2) with a PS-enriched dose ( $\sim 2 \mathrm{~g}$ /day) from two sources (food PS-source ingredient and commercial standard) using microbiota from lean and obese populations. Fecal sterols, short chain fatty acids (SCFA) and microbiota composition were determined by GC/MS, IEC, and 16S-sequencing, respectively.

PS-feeding decreased coprostanol and ethylcoprostanol concentration and increased the production of acetate and butyrate (mainly with lean microbiota). In addition, the PS-enrichment dose increased the proportion of some genera from phylum Firmicutes with lean and obese microbiota.

The results obtained suggest that the gut microbiota preferably use PS as a substrate. In addition, PS-enrichment dose had no effect on the production of SCFA but modified the microbial profile of lean and obese populations.
\end{abstract}

\section{Introduction}

The daily dietary intake of PS (160-400 mg/day) (Gylling et al., 2014; Lagarda, García-Llatas, \& Farré, 2006) does not reach the established levels to have a hypocholesterolemic effect (1.5-3.0 g/day) (Commission Regulation (EU), 2014). Therefore, the mentioned levels can only be achieved by incorporating PS-enriched foods to the usual diet (such as, yellow fat spreads, salad dressings, milk type products, fermented milk products, soya drinks, cheese type products, rye bread and rice drinks).

While dietary cholesterol is absorbed between 20 and $80 \%$ (de Boer, Kuipers, \& Groen, 2018; Stellaard \& Lütjohann, 2015), the intestinal absorption rate of total PS is only $2-3 \%$ (García-Llatas \& RodríguezEstrada, 2011). Non-absorbed sterols reach the colon and can be biotransformed by the gut microbiota. Although cholesterol biotransformation mediated by gut microbiota has been widely studied using in vitro assays (Wong, 2014), less information is available on the biotransformation of PS and their possible impact (in the case of high intake levels) on colonic microbial metabolization of other substrates.
There is an important association between colonic microbiota and host, and the microbiota has been acknowledged as a metabolic organ (Bäckhed et al., 2004). A well-balanced intestinal microbiota has been shown to be important for the health of the host (e.g. increased colonization resistance, stimulation of the immune system, support in digestion, synthesis of nutrients and production of butyrate for enterocytes) (Portune, Benítez-Páez, Del Pulgar, Cerrudo, \& Sanz, 2017). The metabolic function of the microbiota highly depends on the type of substrates available to be fermented. The major fermentation processes in the colon are saccharolytic and proteolytic fermentation. However, there are many more dietary components that make it to the colon and are fermented, but there are few studies on the lipolytic fermentation process, and specifically on PS (Bernalier-Donadille, 2010).

On the other hand, overweight and obesity constitute the main risk factors for a wide range of chronic disorders, including diabetes (with a $44 \%$ increased risk in obese subjects), cardiovascular disease (23\%), and cancer (41\%) (Bray, 2004; WHO, 2018). Some studies in humans (Ley, Turnbaugh, Klein, \& Gordon, 2006; Turnbaugh et al., 2009) and animals (Bäckhed et al., 2004; Ley et al., 2005; Turnbaugh et al., 2006)

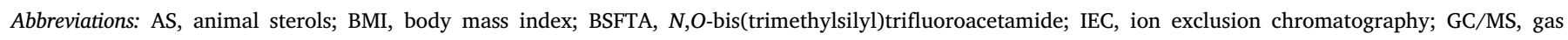

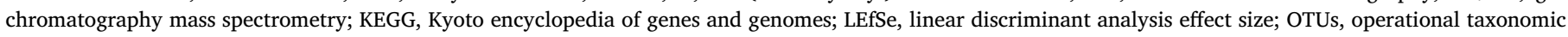

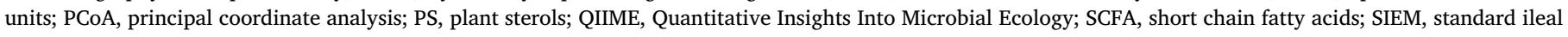
efflux medium; TIM-2, TNO intestinal model-2; TMCSL, trimethylchlorosilane; TMSE, trimethylsilyl ether

* Corresponding author.

E-mail address: amparo.alegria@uv.es (A. Alegria).
} 
have associated the intestinal microbial dysbiosis with obesity. In general, obese individuals show a decrease in bacterial diversity (Kasai et al., 2015; Lau, Carvalho, Pina-Vaz, Barbosa, \& Freitas, 2015; Mishra, Dubey, \& Ghosh, 2016; Turnbaugh et al., 2009) characterized by an increase in the Firmicutes-Bacteroidetes ratio (Boulangé, Neves, Chilloux, Nicholson, \& Dumas, 2016; Gerard, 2016; Kasai et al., 2015; Lau et al., 2015; Lecomte et al., 2015).

In the present study, the validated dynamic in vitro proximal colon model developed by The Netherlands Organization for Applied Scientific Research (TNO) was used to evaluate the effect of PS-enrichment dose $(2 \mathrm{~g} /$ day) on composition and metabolic functions of microbiota from lean and obese subjects, since there are no in vitro fermentation studies by a dynamic system and with PS-enriched medium and microbiota from lean and obese population.

\section{Material \& methods}

\subsection{Test compounds}

A PS-source ingredient used in enrichment of foods by industry (Lipophytol ${ }^{\oplus} 146 \mathrm{ME}$ Dispersible), which present free microcrystalline PS from tall oil in powder form (Lipofoods SLU, Barcelona, Spain) were used. In addition, a standard of $\beta$-sitosterol $\geq 70 \%$ obtained from Sigma-Aldrich $^{\circledast}$ (Munich, Germany) has also been used. Both test compounds were previously analyzed according to González-Larena et al. (2011). The purity of PS-source ingredient was 54\% (w/w) (sitosterol: $82 \%$, sitostanol: $10 \%$, campesterol: $6.2 \%$, stigmasterol: $1.5 \%$ and campestanol: $0.2 \%$ ), the rest of its composition (46\%, w/w) corresponds to maltodextrin, inulin and sucrose esters. In the analysis of $\beta$ sitosterol $\geq 70 \%, 80 \%$ purity was obtained (sitosterol: $84 \%$, sitostanol: $6.4 \%$ and campesterol 9.1\%) and the remaining $20 \%$ corresponded to other unidentified steroid compounds. Therefore, this standard is called "PS-mixture standard" throughout the manuscript. Besides, the PSmixture standard was chosen because their PS composition was similar to the PS-source ingredient and thus know the behaviour of PS without matrix interference.

PS from the PS-source ingredient were micro-encapsulated with maltodextrin, inulin and sucrose esters, thus it was necessary to carry out an acidification ( $\mathrm{pH} 2,37^{\circ} \mathrm{C}$ with a water bath) for $2 \mathrm{~h}$ on the same day prior to introduction of the test compounds in the system, to degrade the carbohydrates capsule. It was considered appropriate to apply this acidification also to the PS-mixture standard and control (without PS and commented below in Section 2.4), so all experiments were treated under the same conditions. Taking into account the purity of test compounds, the acidification was carried out on $4 \mathrm{~g}$ of PS-source ingredient and $2.5 \mathrm{~g}$ of PS-mixture standard in glass jars $(100 \mathrm{~mL})$ and in the case of control experiment, the glass jar was empty. Then, at each experiment, $\mathrm{NaCl} 0.85 \%(20 \mathrm{~mL})$, Tween $80(0.5 \mathrm{~g})$ and $\mathrm{HCl} 1 \mathrm{M}$ (160 $\mu \mathrm{L}$ for PS-source ingredient, $140 \mu \mathrm{L}$ for PS-mixture standard and $120 \mu \mathrm{L}$ for control experiment) were added. After acidification the $\mathrm{pH}$ was adjusted to 5.8 , the final volume was $30 \mathrm{~mL}$, which was collected with a sterile plastic syringe.

\subsection{Microbiota: source, collection and processing}

Homogenates of human feces were made from subgroups of healthy volunteers who were selected according to their body mass index (BMI). The group of participants had not used prebiotics or probiotics in the 2 weeks prior to the donation and had not taken antibiotics and PSsupplements or enriched foods for at least 3 months.

Lean participants: five donors ( 3 women and 2 men) with a mean age of $27.2 \pm 4.3$ years, an average weight of $61.6 \pm 3.9 \mathrm{~kg}$ and a mean BMI of $21.7 \pm 0.8$. Obese participants: thirteen donors (7 women and 6 men) with a mean age of $55.1 \pm 9.8$ years, an average weight of $100.0 \pm 12.9 \mathrm{~kg}$ and mean BMI of $33.2 \pm 3.5$.

All the donors collected a fresh fecal sample in a gastight bag and placed it immediately into a plastic jar containing an anaerobic strip (AnaeroGen $^{\mathrm{TM}}$, Cambridge, UK). Samples were transported in a period not longer than $5 \mathrm{~h}$ to the laboratory, were homogenized and mixed under strict anaerobic conditions (Sheldom Lab-Bactron IV, Cornelius, OR, USA) to create a standardized microbiota stock according to Aguirre, Jonkers, Troost, Roeselers, and Venema (2014). Mixing was done with a dialysate solution (content per litre: $2.5 \mathrm{~g} \mathrm{~K}_{2} \mathrm{HPO}_{4} \cdot 3 \mathrm{H}_{2} \mathrm{O}$, $4.5 \mathrm{~g} \mathrm{NaCl}, 0.005 \mathrm{~g} \mathrm{FeSO}_{4} \cdot 7 \mathrm{H}_{2} \mathrm{O}, 0.5 \mathrm{~g} \mathrm{MgSO}_{4} \cdot \mathrm{H}_{2} \mathrm{O}, 0.45 \mathrm{~g} \mathrm{CaCl}_{2} \cdot 2 \mathrm{H}_{2} \mathrm{O}$, $0.05 \mathrm{~g}$ ox bile, $0.4 \mathrm{~g}$ cysteine hydrochloride; $\mathrm{pH} 5.8$ ), with $1 \mathrm{~mL}$ of a vitamins mixture (content per litre: $1 \mathrm{mg}$ menadiona, $2 \mathrm{mg}$ D-biotin, $0.5 \mathrm{mg}$ vitamin $\mathrm{B} 12,10 \mathrm{mg}$ pantothenate, $5 \mathrm{mg}$ nicotinamide, $5 \mathrm{mg} p$ animobenzoic acid and $4 \mathrm{mg}$ thiamine), and glycerol $(14 \% \mathrm{w} / \mathrm{w})$ as cryoprotective agent. Fecal suspension was aliquoted $(35 \mathrm{~mL})$, frozen in liquid nitrogen, and stored at $-80^{\circ} \mathrm{C}$ until inoculation in TIM-2. Before being introduced into the system, the inoculum was thawed during $1 \mathrm{~h}$ in a $37^{\circ} \mathrm{C}$ in a water bath (Aguirre et al., 2015). Subsequently, in the anaerobic chamber the aliquot $(35 \mathrm{~mL})$ of fecal suspension was diluted with dialysate $(1: 1, \mathrm{v} / \mathrm{v})$ and $60 \mathrm{~mL}$ transferred to a sterile plastic syringe. This was used as the inoculum of the TIM-2 unit.

\subsection{Standard ileal efflux medium (SIEM)}

SIEM contained the following components: $100 \mathrm{~g}$ CHO medium (per litre: $12 \mathrm{~g}$ pectine, $12 \mathrm{~g}$ xylan, $12 \mathrm{~g}$ arabinogalactan, $12 \mathrm{~g}$ amylopectine, $100 \mathrm{~g}$ starch), $25 \mathrm{~g}$ TBCO 6.25x (per litre: $270 \mathrm{~g}$ Tween $80,375 \mathrm{~g}$ bactopepton, $375 \mathrm{~g}$ casein, $6.25 \mathrm{~g}$ ox-bile), $2 \mathrm{~g} \mathrm{MgSO}_{4}(50 \mathrm{~g} / \mathrm{L}$ ), $2 \mathrm{~g}$ cysteine $(20 \mathrm{~g} / \mathrm{L}), 0.2 \mathrm{~mL}$ vitamin mixture (mentioned above), $4 \mathrm{~mL}$ salts solution $\left(4.7 \mathrm{~g} \mathrm{~K} \mathrm{~K}_{2} \mathrm{HPO}_{4} \cdot 3 \mathrm{H}_{2} \mathrm{O}, 8.4 \mathrm{~g} \mathrm{NaCl}, 0.8 \mathrm{~g} \quad \mathrm{CaCl}_{2} \cdot 2 \mathrm{H}_{2} \mathrm{O}, 0.009 \mathrm{~g}\right.$ $\mathrm{FeSO}_{4} \cdot 7 \mathrm{H}_{2} \mathrm{O}, 0.02 \mathrm{~g}$ haemin) and antifoam B emulsion (Sigma-Aldrich ${ }^{\circledR}$, Munich, Germany). The $\mathrm{pH}$ was adjusted to 5.8. SIEM simulates material passing the ileocecal valve in humans, or in other words material reaching the colon, and was used during the period of microbiota standardization and to feed the system during fermentation period for three experiments (control, PS-source ingredient and PS-mixture standard) (Fig. 1).

\subsection{TIM-2 fermentation assays}

The TIM-2 system is a validated dynamic, computer-controlled model which simulates the human proximal colon, mimicking body temperature $\left(37^{\circ} \mathrm{C}\right)$, lumen $\mathrm{pH}(5.8)$, absorption of water and microbial metabolites through a semipermeable membrane inside de model, mixing and transporting the intestinal contents with peristaltic movements, anaerobic conditions by flushing with gaseous $\mathrm{N}_{2}$, and using an microbiota from human origin (Maathuis, Hoffman, Evans, Sanders, \& Venema, 2009; Venema, Vermunt, \& Brink, 2005).

All experiments (PS-source ingredient, PS-mixture standard and control) were performed in duplicate. At the start of each experiment, the model was inoculated with approximately $60 \mathrm{~mL}$ of the standardized microbiota from lean or obese donors and $60 \mathrm{~mL}$ of dialysate (see Section 2.2). SIEM was fed at a rate of $2.5 \mathrm{~mL} / \mathrm{h}$. The microbiota was allowed to adapt to the model conditions and SIEM for $16 \mathrm{~h}$ and after that, a $4 \mathrm{~h}$ starvation period allowed the bacteria to ferment all available carbohydrates in the system prior to the addition of the test compounds (Fig. 1). After the starvation period, samples of lumen and dialysate were collected at time-point zero (t0), and SIEM was fed in all units of the system (feeding rate: $60 \mathrm{~mL} /$ day $-2.5 \mathrm{~mL} / \mathrm{h}$ ). Acidified samples of PS-source ingredient, PS-mixture standard $(2 \mathrm{~g} /$ day $)$ and control (without PS) (see Section 2.1) collected in the syringe were introduced through the sampling port each day. After 24,48 and $72 \mathrm{~h}$, samples of the lumen and dialysate were collected, as is shown in Fig. 1. A total lumen sample of $30 \mathrm{~mL}$ was removed from the system to simulate passage of material from the proximal to the distal colon. 




SIEM: Standard Ileal Efflux Medium; PS: Plant Sterol

Fig. 1. Experimental design.

\subsection{Analytical methods}

\subsubsection{Fecal sterols}

Fecal sterols and their metabolites were determined according to Cuevas-Tena, Alegría, and Lagarda (2017). Briefly, the samples were diluted with MilliQ water (1:100) and volumes from $25 \mu \mathrm{L}$ to $200 \mu \mathrm{L}$ were needed for those samples with large amounts of PS (PS-source ingredient and PS-mixture standard 24, 48 or $72 \mathrm{~h}$ ), and volumes between 1 and $3 \mathrm{~mL}$ were taken mainly for the analysis of samples at time zero and control. The analysis was performed in triplicate using $5 \alpha-$ cholestane $(20 \mu \mathrm{g})$ as internal standard. The saponification step was carried out with $1 \mathrm{~mL}$ of ethanolic potassium hydroxide solution $0.71 \mathrm{M}$ $\left(65^{\circ} \mathrm{C} / 1 \mathrm{~h}\right)$ using a block heater. The unsaponifiable fraction was extracted with $0.5 \mathrm{~mL}$ of Milli-Q water and $2 \mathrm{~mL}$ of n-hexane (centrifuged at $18{ }^{\circ} \mathrm{C} / 10 \mathrm{~min} / 3600 \mathrm{rpm}$ ). The $\mathrm{n}$-hexane extraction step was performed twice under the same conditions as described above. The organic extracts were evaporated to dryness under nitrogen. In order to obtain the trimethylsilyl ether (TMSE) derivatives, $200 \mu \mathrm{L}$ of BSTFA + 1\% TMCS:pyridine 10:3 (v/v) were added $\left(65^{\circ} \mathrm{C} / 1 \mathrm{~h}\right)$. The TMSE derivatives obtained were dissolved with $3 \mathrm{~mL}$ of $\mathrm{n}$-hexane, filtered (Millex-FH filter unit, $0.45 \mu \mathrm{m}$ Millipore, Milford, MA, USA), evaporated under nitrogen, and dissolved in $40 \mu \mathrm{L}$ of n-hexane. One $\mu \mathrm{L}$ of this solution was injected into a GC/MS (Thermo Science Trace ${ }^{\circledR}$ GCUltra with ion trap ITQ 900, Waltham, MA, USA) with a CP-Sil8 CB low bleed/MS $(50 \mathrm{~m} \times 25 \mathrm{~mm} \times 0.25 \mu \mathrm{m})$ column (Agilent Technologies ${ }^{\circledR}$, CA, USA). Hydrogen was used as carrier gas, operating at a constant flow of $1 \mathrm{~mL} / \mathrm{min}$. The mass spectrometer operated at $-70 \mathrm{eV}$, and a mass range from 50 to $650 \mathrm{~m} / z$ was scanned.

\subsubsection{SCFA, lactate and succinate}

Both lumen $(1.5 \mathrm{~mL})$ and dialysate $(2 \mathrm{~mL})$ were centrifuged at $14,000 \mathrm{rpm}$ for $10 \mathrm{~min}$, filtered through a $0.45 \mu \mathrm{m}$ PFTE filter, and diluted in the mobile phase ( $1.5 \mathrm{mM}$ aqueous sulfuric acid). Ten microliters were loaded into the column with the help of an automatic sampler 730 (Metrohm, Herisa, Switzerland). The acids were eluted according to their $\mathrm{pKa}$. The analysis was carried out by ion exclusion chromatography (IEC) using an 883 chromatograph (IC, Metrohm,) equipped with a Transgenomic IC Sep ICE-ION-300 column $(30 \mathrm{~cm} \times 7.8 \mathrm{~mm} \times 7 \mu \mathrm{m})$ and a MetroSep RP2 Guard. A column flow of $0.4 \mathrm{~mL} / \mathrm{min}$ with a column temperature of $65^{\circ} \mathrm{C}$ was used. The acids were detected using suppressed conductivity detection. The company Brightlabs (Venlo, The Netherlands) carried out these analyses.

\subsubsection{Gut microbiota}

The isolation of genomic DNA from the fecal samples ( $3 \mathrm{~mL}$ lumen) was performed using standard molecular biology kits from ZYMO Research provided by BaseClear (Leiden, The Netherlands). The PCR amplification of the 16S rRNA gene (V3 and V4 regions), the barcoding and the library preparation were carried out by BaseClear. The sequencing was carried out using the Illumina MiSeq system and later the sequences were converted into FASTQ files using BCL2FASTQ pipeline version 1.8.3. The quality cut was applied based on the quality level of Phred (Phred quality score). Quantitative Insights Into Microbial Ecology (QIIME) software package (1.9.0) was used for microbial analyses (Caporaso et al., 2010). The sequences were classified using Greengenes (version 13.8) as a reference 16S rRNA gene database. Linear discriminant analysis effect size (LEfSe) (Segata et al., 2011) was used to find biomarkers between groups using relative abundances from the operational taxonomic unit (OTU) tables generated in QIIME. Phylogenetic Investigation of Communities by Reconstruction of Unobserved States (PICRUSt) (Langille et al., 2013) was used to predict the gene families contributing to the metagenomes of the samples identified using 16S rRNA sequencing. This data was visualized using statistical analysis of taxonomic and functional profiles (STAMP) (Parks, Tyson, Hugenholtz, \& Beiko, 2014).

\subsection{Statistical analysis}

Changes in fecal sterols, SCFA and lactate after in vitro colonic fermentation assays during 3 days were evaluated by ANOVA and means were compared by an LSD test (confidence level 95.0\%) using Statgraphics Centurion XVI.I package. The software package R (3.5.0) (R Core Team, 2013) was used to determine correlations between OTUs and metabolites. Statistical analyses were performed with RStudio. Spearman correlation was calculated between the relative abundance of OTUs and continuous variables (fecal sterols and SCFA). Multiple comparison was corrected using the false discovery rate (FDR), and qvalues (adjusted p-values) were considered significantly different at $<0.05$. Correlation between OTUs and metabolites are indicated by the rho-value. 
Table 1

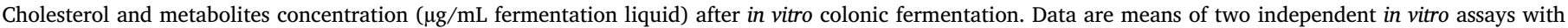

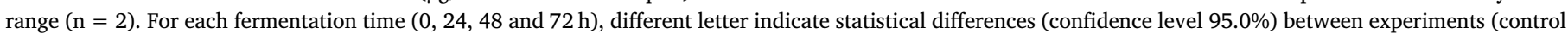
vs. PS-source ingredient $v s$. PS-mixture standard) for lean (a-c) and obese (x-z) microbiota.

\begin{tabular}{|c|c|c|c|c|c|c|}
\hline & \multicolumn{3}{|l|}{ Lean } & \multicolumn{3}{|l|}{ Obese } \\
\hline & Control & PS-source ingredient & PS-mixture standard & Control & PS-source ingredient & PS-source standard \\
\hline \multicolumn{7}{|c|}{ Cholesterol } \\
\hline $\mathrm{Oh}$ & $123.1(94.0-152.2) a$ & $133.2(113.9-152.5) \mathrm{a}$ & $159.2(114.8-203.5) \mathrm{a}$ & $106.6(84.1-129.0) x$ & $241.6(172.2-311.0) \mathrm{x}$ & $106.9(74.4-139.4) x$ \\
\hline $24 \mathrm{~h}$ & $43.8(40.3-47.3) \mathrm{a}$ & $173.2(157.3-189.2) \mathrm{b}$ & $94.0(89.4-98.5) c$ & $52.8(46.4-59.2) \mathrm{x}$ & $132.2(130.6-133.7) y$ & $112.7(110.2-115.6) \mathrm{z}$ \\
\hline $48 \mathrm{~h}$ & $39.2(22.5-55.9) \mathrm{a}$ & 93.2 (80.9-105.5)a & $63.1(52.1-74.1) a$ & $46.9(34.9-59.0) x$ & $102.4(94.6-110.2) y$ & $116.3(105.8-126.7) y$ \\
\hline $72 \mathrm{~h}$ & $27.4(19.4-35.4) \mathrm{a}$ & $106.5(95.4-117.5) b$ & $75.4(71.0-79.8) \mathrm{b}$ & $57.7(55.8-59.6) x$ & $74.9(71.0-78.8) x y$ & $79.0(73.8-84.1) y$ \\
\hline \multicolumn{7}{|c|}{ Coprostanol } \\
\hline $0 \mathrm{~h}$ & 116.6 (91.6-141.5)a & 112.1 (102.9-121.3)a & $124.2(89.1-159.2) a$ & $283.7(221.4-346.0) x$ & $500.7(401.9-599.6) x$ & $447.8(299.8-595.9) x$ \\
\hline $24 \mathrm{~h}$ & 127.7 (108.1-147.3)a & 115.5 (114.7-116.3)ab & $66.3(66.2-66.4) \mathrm{b}$ & $102.0(99.5-104.6) x$ & $241.2(221.0-261.3) y$ & $163.1(151.5-174.8) \mathrm{z}$ \\
\hline $48 \mathrm{~h}$ & $39.3(29.2-49.4) \mathrm{a}$ & 59.8 (47.9-71.7)a & 46.2 (42.9-49.5)a & $111.6(84.3-138.8) x$ & $277.2(275.3-278.6) y$ & $228.8(207.6-250.0) y$ \\
\hline $72 \mathrm{~h}$ & $100.6(92.5-108.8) a$ & $66.7(57.3-76.0) \mathrm{b}$ & $48.3(47.0-49.8) b$ & $134.3(129.5-139.0) x$ & $225.9(217.6-234.2) y$ & $178.9(178.1-179.6) \mathrm{z}$ \\
\hline \multicolumn{7}{|c|}{ Coprostanone } \\
\hline $0 \mathrm{~h}$ & $31.4(30.5-32.4) \mathrm{a}$ & $32.0(31.2-32.8) \mathrm{a}$ & $36.8(34.8-38.9) a$ & $169.1(168.3-169.9) x$ & $248.6(203.4-293.8) x$ & $330.4(242.8-418.1) x$ \\
\hline $24 \mathrm{~h}$ & $51.8(51.2-52.5) \mathrm{a}$ & $39.3(38.5-40.1) b$ & $39.8(37.9-41.6) b$ & $61.3(58.4-64.1) x$ & $60.7(55.2-66.3) \mathrm{x}$ & $55.0(54.8-55.2) \mathrm{x}$ \\
\hline $48 \mathrm{~h}$ & $40.6(38.2-43.0) \mathrm{a}$ & 39.5 (39.4-39.6)a & $45.4(44.9-46.0) a$ & $72.9(54.2-91.6) x$ & $53.4(51.4-55.4) x$ & $65.3(57.0-73.6) \mathrm{x}$ \\
\hline $72 \mathrm{~h}$ & $74.3(44.5-104.1) a$ & 75.6 (75.5-75.7)a & $77.0(76.8-77.2) a$ & $61.1(57.0-65.2) x$ & $54.1(51.9-56.3) x$ & $51.0(49.5-52.5) x$ \\
\hline \multicolumn{7}{|c|}{ Cholestanol } \\
\hline $0 \mathrm{~h}$ & $7.6(5.9-9.2) a$ & $8.0(7.1-8.9) a$ & $7.2(6.5-7.8) \mathrm{a}$ & $14.7(13.1-16.2) x$ & $23.9(20.2-27.6) x$ & $21.5(18.4-24.6) x$ \\
\hline $24 \mathrm{~h}$ & $8.5(7.8-9.3) a$ & $9.6(8.7-10.5) a$ & $7.0(6.6-7.4) \mathrm{a}$ & $8.2(7.8-8.5) \mathrm{x}$ & $16.4(15.1-17.7) y$ & $12.9(12.4-13.4) y$ \\
\hline $48 \mathrm{~h}$ & $6.3(4.8-7.7) \mathrm{a}$ & $7.4(7.2-7.5) \mathrm{a}$ & $0.01(0.0005-0.02) a$ & $8.7(6.9-10.4) x$ & $14.4(10.1-18.7) x$ & $17.1(16.1-18.2) \mathrm{x}$ \\
\hline $72 \mathrm{~h}$ & $7.3(7.0-7.6) \mathrm{a}$ & $10.2(10.1-10.2) \mathrm{b}$ & $9.2(8.3-9.5) b$ & $10.6(10.3-10.8) x$ & $16.6(16.4-16.9) y$ & $13.0(12.7-13.4) y$ \\
\hline
\end{tabular}

\section{Results}

\subsection{Microbiota effect on sterols}

\subsubsection{Fecal sterols}

Tables from 1 to 3 show the mean concentrations $(\mu \mathrm{g} / \mathrm{mL})$ of fecal sterols and metabolites present in control, PS-source ingredient and PSmixture standard experiments, during the fermentation period $(0-72 \mathrm{~h})$ using microbiota from lean and obese population.

A significant increase $(\mathrm{p}<0.05)$ in cholesterol concentration $(\mu \mathrm{g} /$ $\mathrm{mL}$ ) was observed in the experiments with PS-source ingredient (24 and $72 \mathrm{~h}$ ) or PS-mixture standard (24, 48 and $72 \mathrm{~h}$ ) with respect to the control experiment and independently of the microbiota used (Table 1). In the assays with lean population microbiota there was a significant decrease in coprostanol (24 and $72 \mathrm{~h}$ ) and coprostanone (24h) concentrations in experiments with PS-source ingredient or PS-mixture standard compared to control. In addition, a significant increase $(\mathrm{p}<0.05)$ in cholestanol $(72 \mathrm{~h})$ concentration is also observed between experiments with a medium enriched in PS and control (Table 1). When microbiota of obese population were used, there was a significant increase in concentrations of coprostanol $(24,48$ and $72 \mathrm{~h})$ and cholestanol (24 and $72 \mathrm{~h}$ ) in the experiments with PS-source ingredient or PS-mixture standard compared to control (Table1).

Taking into account the entire fermentation period (0-72 h), cholesterol concentration decrease in control $(77 \%$ for lean microbiota and $45 \%$ for obese microbiota), PS-source ingredient (20\% and $69 \%)$ and PS-mixture standard (32 and 26\%) when using lean and obese microbiota, respectively. It should be noted that all metabolites (coprostanol, coprostanone and cholestanol) were higher in obese than in lean microbiota assays. In addition, the coprostanol concentration throughout the fermentation period $(0-72 \mathrm{~h})$ decreased in control $(13 \%$ for lean and $52 \%$ for obese), PS-source ingredient (41 and 55\%) and PS-mixture standard (61 and 60\%). However, coprostanone concentration at the end of fermentation period $(72 \mathrm{~h})$ increased in experiments with PSsource ingredient (136\%) and PS-mixture standard (109\%) when lean microbiota was used. In the assays with obese microbiota, the coprostanone concentration decreased from time zero to $24 \mathrm{~h}$ (control: $64 \%$; PS-source ingredient: 76\%; PS-mixture standard: 83\%) and then the concentration remained more or less equal until $72 \mathrm{~h}$ for all experiments. In the case of cholestanol concentrations, at the end of fermentation period using lean microbiota, their concentration increased in experiments with PS-source ingredient (27\%) and PS-mixture standard (29\%), while in the assays with obese microbiota, their concentration decreased in presence of PS-source ingredient (30\%) and PS-mixture standard (40\%).

The mean concentration of sitosterol and campesterol and their metabolites in control, PS-source ingredient and PS-mixture standard experiments, during the fermentation period $(0-72 \mathrm{~h})$ using microbiota from lean and obese population are show in Table 2 and Table 3, respectively.

A significant increase $(\mathrm{p}<0.05)$ in the concentration of sitosterol, sitostanol, campesterol and campestanol in presence of PS-source ingredient and PS-mixture standard compared to control was observed in all fermentation times (24, 48 and $72 \mathrm{~h}$ ) (Tables 2 and 3).

Ethylcoprostanol decreased significantly $(\mathrm{p}<0.05)$ during all fermentation period $(24-72 \mathrm{~h})$ in experiments with PS-source ingredient (32\% for lean and $88 \%$ for obese) or PS-mixture standard (35\% for lean and $87 \%$ for obese) compared to control. A significant increase (p $<0.05$ ) of ethylcoprostanone was observed with PS-source ingredient (46 and 35 fold more) and PS-mixture standard (21 and 33 fold more) respect to control when microbiota of lean and obese subjects was used, respectively (Table 2). In the case of methylcoprostanone, a significant increase $(\mathrm{p}<0.05)$ of their concentration was observed from 24 to $72 \mathrm{~h}$ with PS-source ingredient (8 fold more) and PS-mixture standard (25 fold more) (Table 3) using lean microbiota. When obese microbiota was used, the methylcoprostanone concentration increased significantly only between control and PS-mixture standard after $24 \mathrm{~h}$ of fermentation.

\subsection{Production of microbial metabolites}

\subsubsection{SCFA, succinate and lactate}

The average cumulative amount of individual SCFA (acetate, propionate and butyrate), succinate and lactate produced during the fermentation period (24, 48 and $72 \mathrm{~h}$ ) in control, PS-source ingredient and PS-mixture standard experiments using microbiota from lean or obese subjects is shown in Fig. 2.

Production of SCFA (acetate, propionate and butyrate) was higher 
Table 2

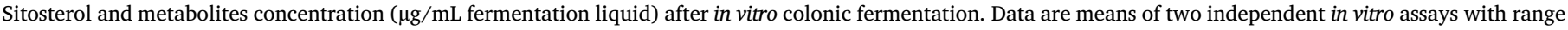

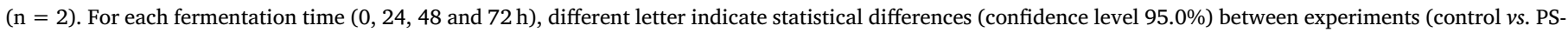
source ingredient $v s$. PS-mixture standard) for lean (a-c) and obese (x-z) microbiota.

\begin{tabular}{|c|c|c|c|c|c|c|}
\hline & \multicolumn{3}{|l|}{ Lean } & \multicolumn{3}{|l|}{ Obese } \\
\hline & Control & PS-source ingredient & PS-mixture standard & Control & PS-source ingredient & PS-mixture standard \\
\hline \multicolumn{7}{|c|}{ Sitosterol } \\
\hline 0 & $36.4(34.5-38.3) \mathrm{a}$ & $35.3(35.1-35.6) \mathrm{a}$ & $59.3(45.0-73.6) \mathrm{a}$ & $36.4(33.8-39.9) x$ & $57.0(38.6-75.3) x$ & $42.6(36.3-48.9) x$ \\
\hline 24 & $45.8(43.7-48.0) a$ & 15760.7 (15664.6-15856.8)b & $7658.0(6573.6-8742.4) c$ & $41.3(39.9-42.8) \mathrm{x}$ & $11382.0(10362.0-12401.9) y$ & $8579.8(8495.3-8664.3) \mathrm{z}$ \\
\hline 48 & $55.3(51.1-59.4) \mathrm{a}$ & 18976.3 (18767.1-19185.6)b & $18552.8(17783.6-19321.9) \mathrm{b}$ & $42.3(41.4-43.3) \mathrm{x}$ & 20492.4 (19171.1-21813.6)y & $17403.5(11228.2-23578.7) y$ \\
\hline 72 & $52.6(43.5-61.7) a$ & 49928.7 (47600.8-52256.6)b & $63621.0(57496.0-69746.0) \mathrm{b}$ & $51.0(49.7-52.3) \mathrm{x}$ & $34395.0(31676.7-37113.3) y$ & 32691.7 (27207.6-38175.8)y \\
\hline \multicolumn{7}{|c|}{ Sitostanol } \\
\hline 0 & $14.8(14.3-15.3) \mathrm{a}$ & $14.3(14.1-14.6) \mathrm{a}$ & 18.3 (15.9-20.8)a & $14.9(14.4-15.4) \mathrm{x}$ & $17.6(14.9-20.3) x$ & $15.6(14.8-16.3) \mathrm{x}$ \\
\hline 24 & $21.3(20.8-21.8) \mathrm{a}$ & $2116.2(2085.1-2147.2) \mathrm{b}$ & $1022.5(858.3-1186.7) \mathrm{c}$ & $20.6(20.3-20.9) x$ & $1762.0(1650.8-1873.1) y$ & $1218.3(1103.3-1333.2) \mathrm{z}$ \\
\hline 48 & $25.3(21.6-29.0) \mathrm{a}$ & 4458.65 (4343.2-4574.1)b & 4825.5 (4444.0-5207.1)b & $21.0(20.7-21.4) x$ & 3016.8 (2849-7-3183.7)y & $2664.8(1868.0-3461.6) y$ \\
\hline 72 & $21.9(21.3-22.5) \mathrm{a}$ & 6908.6 (5893.0-7924.2)b & $6021.8(4557.2-7486.3) \mathrm{b}$ & $22.0(21.8-22.1) x$ & $5816.3(5287.2-6345.4) y$ & $6022.1(4565.2-7478.9) y$ \\
\hline \multicolumn{7}{|c|}{ Ethylcoprostanol } \\
\hline 0 & $19.0(16.2-21.8) \mathrm{a}$ & $20.1(17.8-22.3) \mathrm{a}$ & $23.1(20.0-26.2) \mathrm{a}$ & $35.9(30.3-41.5) x$ & $62.3(48.6-75.9) x$ & $57.1(41.3-72.8) \mathrm{x}$ \\
\hline 24 & $25.6(25.3-25.8) \mathrm{a}$ & $7.8(7.5-8.1) b$ & $9.3(8.2-10.5) \mathrm{b}$ & $16.2(14.8-17.6) \mathrm{x}$ & $10.2(9.8-10.6) y$ & $8.0(7.1-8.8) y$ \\
\hline 48 & $15.1(12.9-17.2) \mathrm{a}$ & $7.1(7.0-7.1) \mathrm{b}$ & $7.4(7.3-7.4) b$ & $18.1(15.9-20.3) x$ & $7.9(7.7-8.1) y$ & $8.0(7.9-8.1) y$ \\
\hline 72 & $24.8(22.0-27.5) \mathrm{a}$ & $13.5(13.4-13.6) \mathrm{b}$ & $15.0(14.4-15.5) b$ & $25.1(24.9-25.3) x$ & $7.3(7.2-7.4) y$ & $7.1(7.1-7.2) y$ \\
\hline \multicolumn{7}{|c|}{ Ethylcoprostanone } \\
\hline 0 & $29.4(28.0-30.8) a$ & $26.3(25.3-27.3) \mathrm{a}$ & $32.2(30.6-33.9) \mathrm{a}$ & $33.7(33.3-34.1) \mathrm{x}$ & $41.1(36.9-45.2) \mathrm{x}$ & $35.9(35.4-36.3) x$ \\
\hline 24 & $39.6(38.7-40.4) a$ & $743.2(743.0-743.5) \mathrm{b}$ & $341.6(311.7-371.5) c$ & $39.6(38.9-40.2) x$ & $805.4(751.6-859.2) y$ & $484.4(431.2-537.5) y$ \\
\hline 48 & $79.6(39.8-119.5) a$ & 1046.4 (889.5-1203.3)9b & $1708.2(1472.9-1943.4) b$ & $38.9(38.0-39.9) \mathrm{x}$ & $1555.5(1475.2-1635.8) y$ & $1243.3(1113.4-1373.31) y$ \\
\hline 72 & $41.8(40.0-43.6) \mathrm{a}$ & 1252.4 (1210.0-1294.9)b & $732.9(633.3-832.6) b$ & $40.5(41.1-40.0) x$ & 1469.7 (1375.9-1563.5)y & 1217.5 (1051.4-1383.5)y \\
\hline
\end{tabular}

in the experiments with microbiota of lean population than obese (Fig. 2). In fact, only statistically significant differences have been detected in assays with lean microbiota. Specifically, a significant increase $(\mathrm{p}<0.05)$ of acetate after 24 and $48 \mathrm{~h}$ of fermentation occurred in the experiments with PS-enriched medium compared to control, being highest under presence of PS-source ingredient. In the case of butyrate, a significant increase $(\mathrm{p}<0.05)$ was only found after $24 \mathrm{~h}$ of fermentation with PS-mixture standard. Lactate only showed a significant increase $(\mathrm{p}<0.05)$ in experiments with PS-source ingredient (net increment: $0.50 \mathrm{mmol}$ ) after $24 \mathrm{~h}$ of fermentation. For propionate and succinate, greater production was observed when PS-source ingredient and PS-mixture standard were used, but no significant differences were found between these two and control.

\subsection{Plant sterol modulation of the microbiota}

Sequencing of the V3-V4 region of 16S rRNA gene was performed and reads were analysed using QIIME. Principal Coordinate Analysis (PCoA) and Linear discriminant analysis effect size (LEfSe) were performed to determine OTUs that were modulated by the interventions. Neither weighted nor unweighted PCoA showed specific clustering by substrate (not shown). Yet LEfSe showed some OTUs that were specific for the treatments. For the lean microbiota, LEfSe only showed OTUs that were more prevalent upon addition of PS-source ingredient (Fig. 3A), which belonged to the genus Catenibacterium. When PSsource ingredient and PS-mixture standard were combined (indicated as Soy) and compared to control, a few more discriminative OTUs were observed (Fig. 3B). Apart from Catenibacterium, Coprococcus was increased upon addition of PS, while Collinsella and Slackia of the Coriobacteriaceae family were increased in control.

Table 3

Campesterol and metabolites concentration ( $\mu \mathrm{g} / \mathrm{mL}$ fermentation liquid) after in vitro colonic fermentation. Data are means of two independent in vitro assays with range $(n=2)$. For each fermentation time $(0,24,48$ and $72 \mathrm{~h})$, different letter indicate statistical differences (confidence level $95.0 \%)$ between experiments (control $v s$. PS-source ingredient $v s$. PS-mixture standard) for lean (a-c) and obese (x-z) microbiota.

\begin{tabular}{|c|c|c|c|c|c|c|}
\hline & \multicolumn{3}{|l|}{ Lean } & \multicolumn{3}{|l|}{ Obese } \\
\hline & Control & PS-source ingredient & PS-mixture standard & Control & PS-source ingredient & PS-mixture standard \\
\hline \multicolumn{7}{|c|}{ Campesterol } \\
\hline 0 & $45.6(44.8-46.4) \mathrm{a}$ & $47.0(45.3-48.8) \mathrm{a}$ & $48.3(46.7-49.9) \mathrm{a}$ & $45.8(45.1-46.6) \mathrm{x}$ & $51.5(48.2-54.8) \mathrm{x}$ & $46.6(44.9-48.3) \mathrm{x}$ \\
\hline 24 & $62.7(62.3-63.1) \mathrm{a}$ & $1649.6(1623.4-1675.8) \mathrm{b}$ & $925.1(883.4-966.8) c$ & $62.6(62.3-62.8) \mathrm{x}$ & $1329.1(1187.0-1471.1) y$ & $961.2(942.0-980.5) y$ \\
\hline 48 & $62.6(60.1-65.2) \mathrm{a}$ & $3372.9(3353.7-3392.0) b$ & $3894.4(3812.4-3976.4) c$ & $62.5(61.3-63.1) \mathrm{x}$ & $2392.9(2310.2-2475.6) y$ & $2257.3(1839.7-2674.8) y$ \\
\hline 72 & $62.1(61.7-62.6) \mathrm{a}$ & $5008.4(4253.6-5763.2) \mathrm{b}$ & 4466.9 (3353.6-5581.3)b & $63.0(62.9-63.1) x$ & $4039.4(3662.8-4415.9) y$ & $4344.6(3330.2-5358.9) y$ \\
\hline \multicolumn{7}{|c|}{ Campestanol } \\
\hline 0 & $14.4(14.1-14.7) a$ & $15.1(14.6-15.6) \mathrm{a}$ & $15.5(14.7-16.2) \mathrm{a}$ & $16.3(15.6-17.1) \mathrm{x}$ & $18.7(17.6-19.9) x$ & $18.5(17.0-20.0) \mathrm{x}$ \\
\hline 24 & $21.2(20.7-21.7) a$ & $255.4(234.1-276.7) b$ & $160.7(156.9-164.6) c$ & $20.4(20.3-20.4) x$ & $284.6(270.8-298.4) y$ & $252.5(250.1-254.9) y$ \\
\hline 48 & $20.4(19.6-21.3) \mathrm{a}$ & $678.0(672.3-683.7) \mathrm{b}$ & $729.4(724.5-734.2) \mathrm{c}$ & $20.6(20.5-20.8) x$ & $552.1(544.9-559.2) y$ & $523.5(476.2-570.8) y$ \\
\hline 72 & $22.9(22.0-23.8) a$ & $826.0(787.0-865.0) b$ & $773.8(650.3-897.2) \mathrm{b}$ & $20.7(20.5-20.9) x$ & $761.4(714.2-808.6) y$ & $793.6(663.3-923.9) y$ \\
\hline \multicolumn{7}{|c|}{ Methylcoprostanone } \\
\hline 0 & - & - & - & $32.3(30.5-34.1) x$ & $34.9(33.5-36.3) x$ & $38.8(37.4-40.2) x$ \\
\hline 24 & - & $10.0(7.9-12.0) \mathrm{a}$ & $8.5(8.5-8.6) a$ & $37.3(36.9-37.7) x$ & $42.2(40.9-43.4) x y$ & $43.5(41.7-45.4) y$ \\
\hline 48 & - & $49.6(44.3-54.9) \mathrm{a}$ & $50.0(49.9-50.1) a$ & $37.2(36.3-38.0) \mathrm{x}$ & $44.0(43.5-44.6) \mathrm{x}$ & $48.9(44.4-53.3) \mathrm{x}$ \\
\hline 72 & - & 87.6 (83.7-91.4)a & $226.1(171.7-280.5) \mathrm{a}$ & $18.4(0.00-36.7) x$ & $23.4(0.00-46.7) x$ & $42.9(42.7-43.2) \mathrm{x}$ \\
\hline
\end{tabular}




\section{Control}
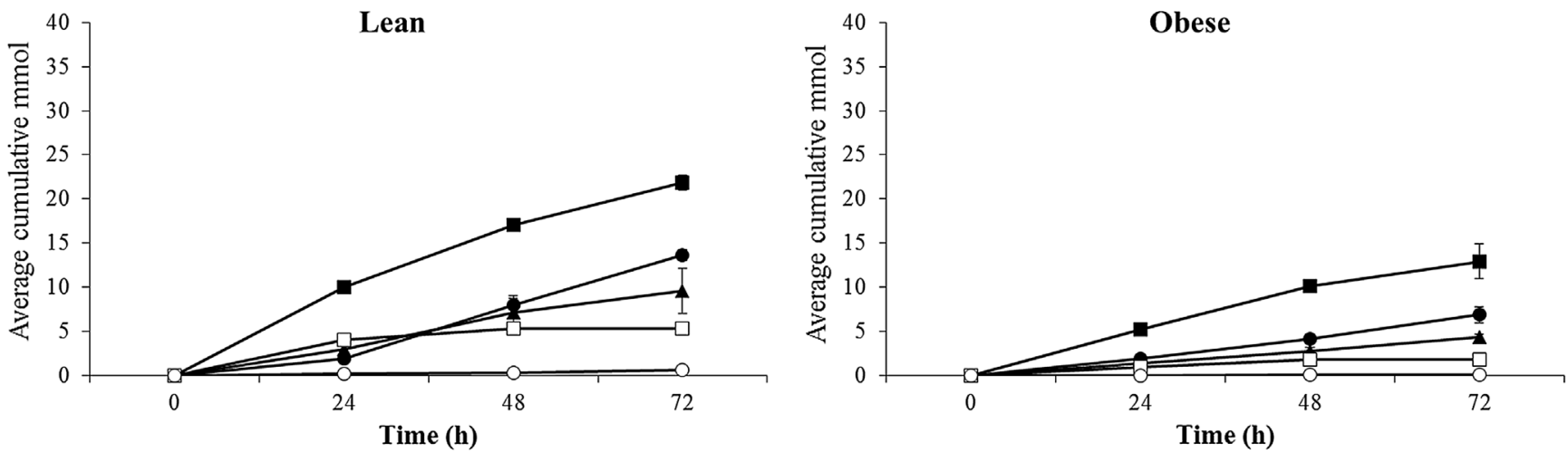

PS-source ingredient
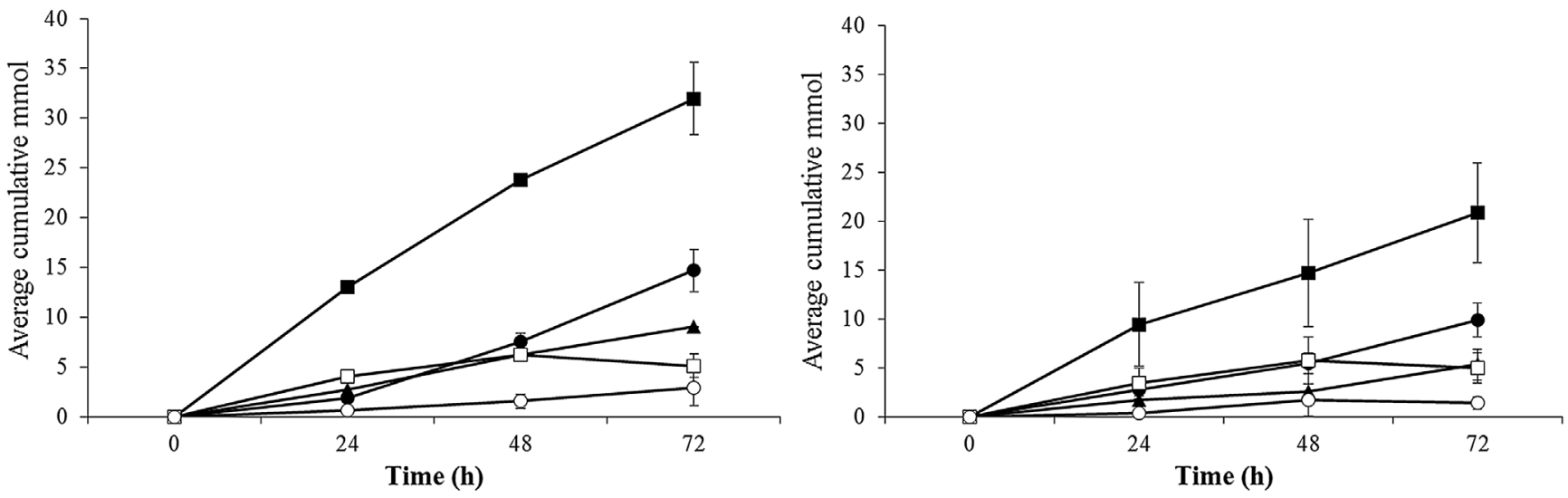

\section{PS-mixture standard}
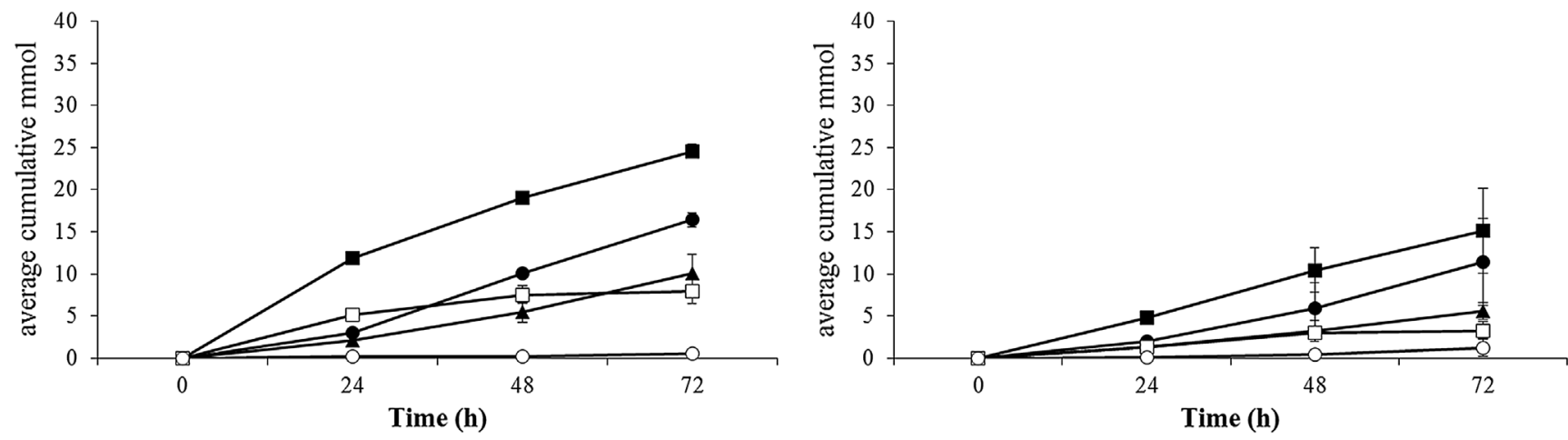

experiments with control, ingredient and standard using lean and obese microbiota. The concentrations at t0 was artificially set to zero.

For the obese microbiota, the genus Clostridium was increased for PS-source ingredient and the kingdom Bacteria for PS-mixture standard, while a few OTUs (including Christensenellaceae and other OTUs in the order Clostridiales) were higher in control (Fig. 3C). Also here, when PSsource ingredient and PS-mixture standard were combined and compared to control, more discriminative OTUs were observed (Fig. 3D).

Using Spearman correlation with false-discovery rate correction, the presence of OTUs was correlated to microbial metabolites produced (Fig. 4, only shown for strong correlations with a rho $>0.666$ or $-0.666>$ rho). For the lean microbiota negative correlations between the genus Dorea and propionate acid, and between an uncharacterized OTU in the order Clostridiales and methylcoprostanone was observed. In addition, positive correlations were found between propionic acid and the genus Atopobium and Peptostreptococcus. In the case of experiments with obese microbiota, there were negative correlations between the genus Klebsiella and butyric acid and methylcoprostanone. The latter metabolite (methylcoprostanone) has also been shown to be negatively correlated with the genus Methanobrevibacter. Other negative correlations recorded were between propionic acid and the Rikenellaceae family, and between butyrate acid and the Ruminococaceae family. Finally, a positive correlation was observed between the genus Bacteroides and methylcoprostanone (Fig. 4).

PICRUSt was used to predict the microbial pathways contributing to the metagenomes of the samples identified using 16S rRNA sequencing, using the Kyoto Encyclopedia of Genes and Genomes (KEGG) database, and the data was visualized using STAMP. Using Welsh's two-sided $t$ - 
A

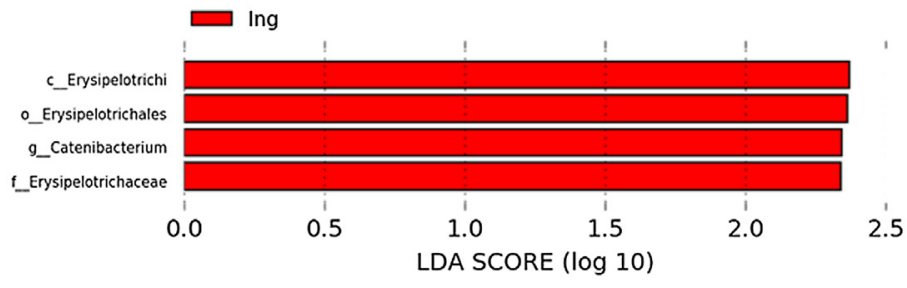

$\mathbf{C}$

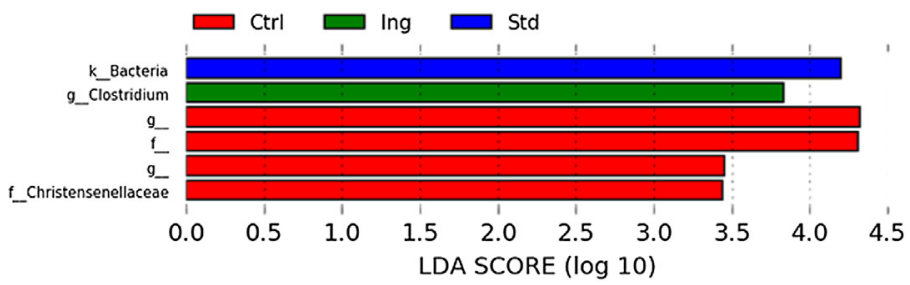

B

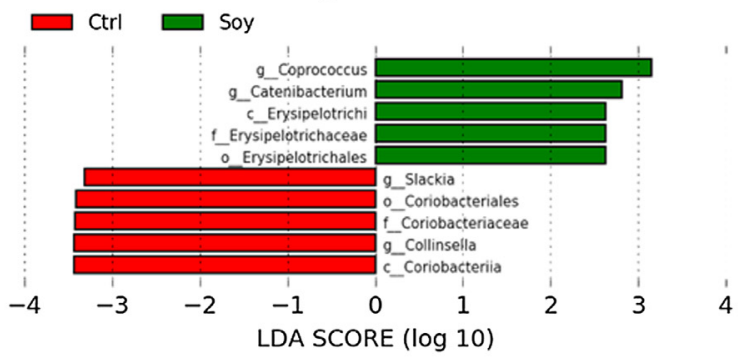

D

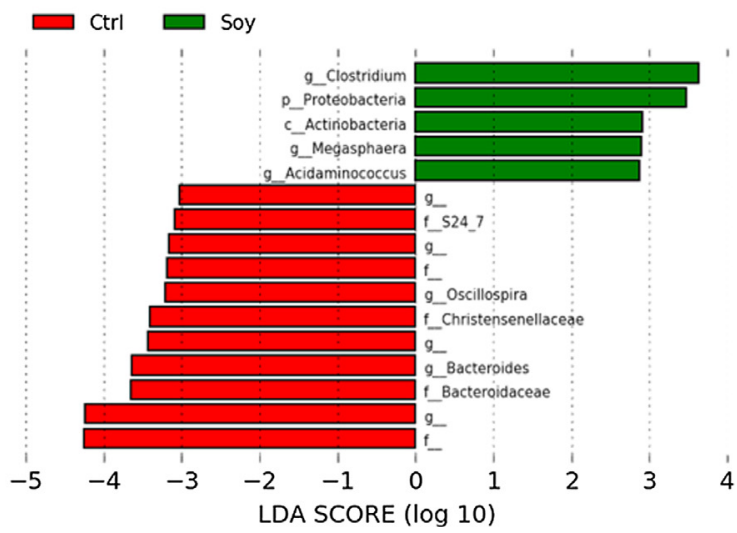

Fig. 3. Linear discriminant analysis effect size for microbiota composition of the lean (A, B) and obese (C, D) microbiota. (Ing: PS-source ingredient; Ctrl: control; Soy: PS-source ingredient + PS-mixture standard; Std: PS-mixture standard).

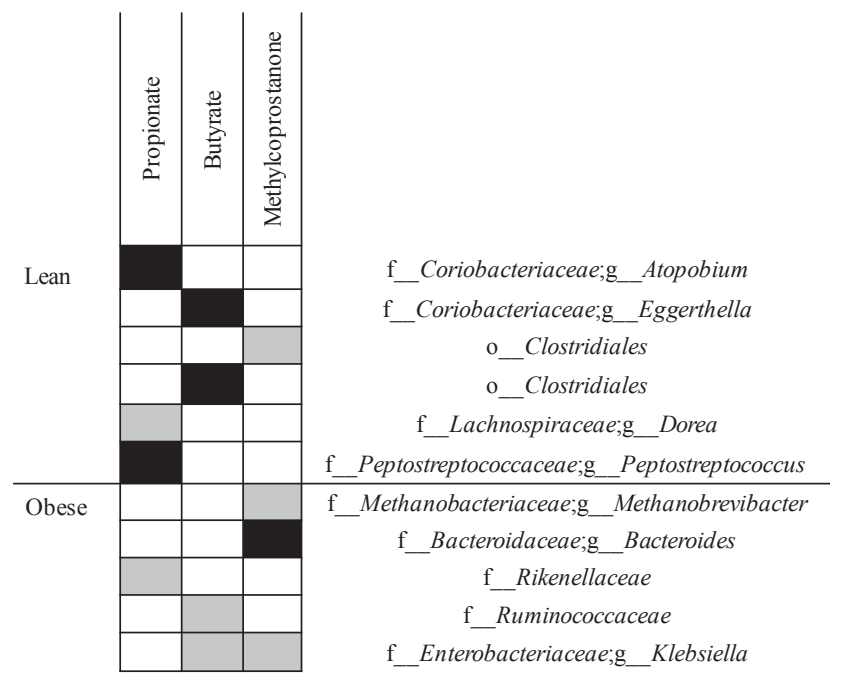

Fig. 4. Spearman correlation with false-discovery rate (FDR) correction between OTUs and some microbial metabolites produced (short chain fatty acids and fecal sterols).

test, pathways predicted for each test product were compared to the other experiments. For the lean microbiota three pathways were significantly different (Table 4A). For the obese microbiota a total of 47 pathways were predicted to be differentially present (Table 4B), including those for flavone and flavonol biosynthesis (Fig. 5A), flavonoid biosynthesis (Fig. 5B). The box-plots in Fig. 5C shows the predicted pathway presence and the heatmap shows the abundance of the pathways in the individual samples.

\section{Discussion}

Given that, coprostanol is the most abundant animal sterol in feces, followed by coprostanone and cholesterol, which can be transformed to a lesser extent into cholestanol (Cuevas-Tena, Alegría, \& Lagarda, 2018), the decrease of coprostanol and coprostanone and increase of cholestanol concentration in PS-source ingredient and PS-mixture standard experiments using microbiota from lean population, suggest that the enrichment of the culture medium with PS has been able to modify the route of cholesterol biotransformation in this assays. In addition, the results obtained also are in concordance with other in vivo studies carried out by Weststrate, Ayesh, Bauer-Plank, and Drewitt (1999), where after the intake of margarine enriched with PS (8.6 g/ day) by healthy subjects, an increase in the concentrations of neutral sterols was found and the amount of cholesterol metabolized into coprostanol was reduced. Cuevas-Tena, Bermúdez, Silvestre, Alegría, and Lagarda (2018) evaluated the impact of intake of a PS-enriched milk based fruit beverage ( $2 \mathrm{~g}$ PS/day) by postmenopausal women on fecal sterols excretion, and found a lower tendency in the production of coprostanol in presence of PS-enrichment dose. In a previous study in rats, following a diet with sitosterol $(0.8 \%, \mathrm{w} / \mathrm{w})$ also a decrease in the coprostanol production compared to a diet containing cholesterol $(1.2 \%$, w/w) was observed (Cohen, Raicht, \& Mosbach, 1974). However, in the assays with obese population microbiota, the increase in the concentration of coprostanol and cholestanol indicate that the cholesterol could have been biotransformed by two different routes (Cuevas-Tena, Alegría, et al., 2018). These facts could also be due to the effect of the diet of the fecal samples donors, since the real sterol intake has not been controlled, and it was not previously consider whether the donors of the fecal samples were high or low sterol converters (Wilkins \& Hackman, 1974), which are limitations in the study.

PS are also transformed by the gut microbiota through biochemical reactions similar to those occurring for cholesterol (Keller \& Jahreis, 2004; Wong, 2014). In this study, the decrease of ethylcoprostanol and the increase of ethylcoprostanone observed in both assays (lean and obese microbiota) under presence of PS-enriched dose suggests that, the capacity of the gut microbiota from both populations was not sufficient 
Table 4

Pathways significantly different between control, PS-source ingredient and PSmixture standard after projecting the OTU abundance on the pathways in KEGG (Kyoto Encyclopaedia of Genes and Genomes) for the lean (A) and obese (B) microbiota.

\begin{tabular}{|c|c|}
\hline Observations Ids & p-values \\
\hline \multicolumn{2}{|l|}{ Lean $(A)$} \\
\hline Phenylpropanoid biosynthesis & 0.03 \\
\hline Starch and sucrose metabolism & 0.04 \\
\hline Transcription related proteins & 0.03 \\
\hline \multicolumn{2}{|l|}{ Obese (B) } \\
\hline Alpha-Linolenic acid metabolism & 0.01 \\
\hline Alzheimer's disease & 0.02 \\
\hline Amytrophic lateral sclerosis (ALS) & 0.02 \\
\hline Apoptosis & 0.01 \\
\hline Bacterial toxins & 0.00 \\
\hline Benzoate degradation & 0.04 \\
\hline Beta-Alanine metabolism & 0.01 \\
\hline Butanoate metabolism & 0.03 \\
\hline Carbohydrate metabolism & 0.04 \\
\hline Chaperones and folding catalysts & 0.004 \\
\hline Chromosome & 0.05 \\
\hline D-Alanine metabolism & 0.02 \\
\hline Dioxin degradation & 0.05 \\
\hline Drug metabolism - other enzymes & 0.03 \\
\hline Electron transfer carriers & 0.01 \\
\hline Fatty acid biosynthesis & 0.02 \\
\hline Flavanone and flavonol biosynthesis & 0.01 \\
\hline Flavonoid biosynthesis & 0.04 \\
\hline Galactose metabolism & 0.01 \\
\hline Glyoxylate and dicarboxylate metabolism & 0.02 \\
\hline Inositol phosphate metabolism & 0.05 \\
\hline Isoquinoline alkaloid biosynthesis & 0.003 \\
\hline Lipoic acid metabolism & 0.03 \\
\hline Membrane and intracellular structural molecules & 0.02 \\
\hline Novobiocin biosynthesis & 0.04 \\
\hline One carbon pool by folate & 0.001 \\
\hline Other glycan degradation & 0.02 \\
\hline Other ion-coupled transporters & 0.04 \\
\hline Other transporters & 0.03 \\
\hline Others & 0.02 \\
\hline Pentose and glucoronate interconversions & 0.02 \\
\hline Pentose phosphate pathway & 0.01 \\
\hline Phosphonate and phosphinate metabolism & 0.02 \\
\hline Polycyclic aromatic hydrocarbon degradation & 0.01 \\
\hline Prenytransferases & 0.02 \\
\hline Pyruvate metabolism & 0.01 \\
\hline Riboflavin metabolism & 0.00 \\
\hline Ribosome biogenesis & 0.02 \\
\hline RNA degradation & 0.05 \\
\hline Sphingolipid metabolism & 0.01 \\
\hline Terpenoid backbone biosynthesis & 0.01 \\
\hline Transcription machinery & 0.01 \\
\hline Transcription related proteins & 0.02 \\
\hline Transporters & 0.03 \\
\hline Tuberculosis & 0.03 \\
\hline Vibrio cholerate pathogenic cycle & 0.03 \\
\hline
\end{tabular}

to transform sitosterol into ethylcoprostanol. This fact is perhaps due to the large amounts of PS present in culture medium (Cohen et al., 1974), causing a lower production of ethylcoprostanol. Similarly, an increase of methylcoprostanone has also been observed with lean microbiota, mainly after $72 \mathrm{~h}$ and in presence of PS-source ingredient and PS-mixture standard (Table 3). Generally, the results suggest that gut microbiota from lean and obese populations would prefer PS as a substrate, because they were present in greater proportion than cholesterol. In the same way, in other in vitro static colon fermentation study of our research group, lower microbial metabolism for cholesterol and higher for sitosterol and campesterol were found (Cuevas-Tena, del Pulgar, et al., 2018). In addition, some studies have suggested that cholesterol metabolites could act as carcinogenic compounds (Hill \& Aries, 1971; Korpela, 1982; Perogambros, Papavassiliou, \& Legakis, 1982; Reddy \& Wynder, 1977).
SCFA are produced in the proximal colon through the fermentation of mainly indigestible carbohydrates. As far as we know, this is the first time that microbial SCFA production is reported after in vitro fermentations assays with PS-enrichment dose with gut microbiota from lean and obese population. In this sense, a greater production of SCFA was observed in experiments with microbiota from lean versus obese subjects, perhaps this fact is due to the different microbial profile of these two populations. However, it has not been possible to establish an association between the genera identified in both trials (lean and obese) and their activity as SCFA producers.

Acetate was the main SCFA produced independently of the type of microbiota (lean or obese) and substrates (control, PS-source ingredient or PS-mixture standard) used. However, this SCFA showed a significantly higher production in presence of PS-enrichment dose using lean microbiota. It has been suggest that acetate stimulates cholesterol and long chain fatty acids synthesis in the liver (Delzenne, Neyrinck, Bäckhed, \& Cani, 2011) and a study using mice showed that acetate from colonic fermentation can cross the blood-brain barrier and suppress appetite in the hypothalamus (Frost et al., 2014). Butyrate is another main SCFA with higher production in experiments with microbiota from lean than obese population. Butyrate functions as the major energy source for colonic epithelial cells (Koenen, Rubio, Mueller, \& Venema, 2016). In addition, this SCFA is considered to be especially important, as it may also play a major role in the prevention of colon cancer (Leonel \& Alvarez-Leite, 2012; Mortensen \& Clausen, 1996; Perrin et al., 2001) and other colonic diseases (Hamer et al., 2008). Besides, butyrate protects against diet-induced obesity and suppresses food intake (Lin et al., 2012). Propionate was also shown to be produced at greater amounts in experiments with microbiota from lean subjects. In the case of this SCFA, it has been suggested that it reduces liponeogenesis, cholesterol synthesis and recently has been demonstrated to be involved in the activation of G-protein coupled receptors (GPR-41 and GPR-43) releasing satiety hormones, thus reducing food intake (Kimura et al., 2011). Succinate and lactate showed to be the minority compounds and a greater production was observed in the experiments with microbiota from lean subjects versus obese. These acids serve as intermediates in the metabolism of SCFA and generally they do not accumulate in the colon (Gibson, Probert, Van Loo, Rastall, \& Roberfroid, 2004). However, a significant increase in lactate production was observed in the presence of PS-source ingredient only in lean microbiota experiment. In this context, lactate only accumulates when there is a fast fermentation of a substrate. If substrates are fermented slowly, lactate is mostly converted into butyrate (Morrison et al., 2006).

Besides, our results indicate that PS influences Catenibacterium and Coprococcus genera (Erysipelotrichaceae family) in experiments with lean microbiota and Clostridium genus in obese microbiota, with an increase in the proportion of these bacteria when PS was added to the culture medium. Regarding to the increase of the Erysipelotrichaceae family members, these results were not coincident with those found in a previous study by our group (Cuevas-Tena, del Pulgar, et al., 2018). In a clinical trial (Baumgartner et al., 2017), where 13 healthy subjects received during three weeks a control or plant stanol ester enriched margarine ( $3 \mathrm{~g}$ /day plant stanols), no differences in gut microbiota composition were recorded between the two target groups. However, van Faassen et al. (1987) found slight changes for Bifidobacterium, Bacteroides and Clostridium genera in subjects with a vegan diet, which was rich in PS and dietary fiber, which affect gut microbiota composition.

Previously were not established a similar age range between the donors of the lean and obese population and not to considered also the enterotypes (Arumugam et al., 2011) of the microbial profile for fecal samples used as inoculum, which constitute limitations for the study. 
A



$\mathbf{C}$

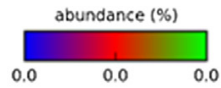

B

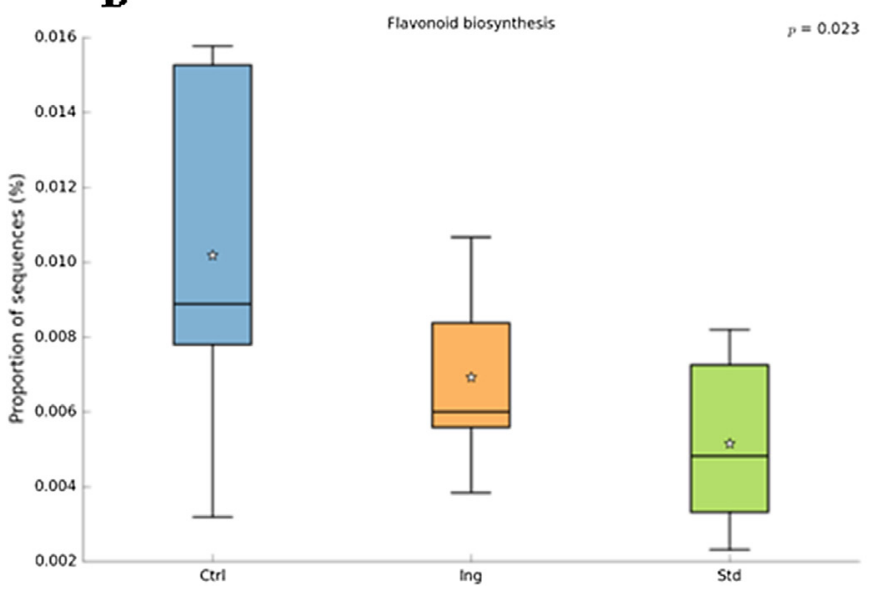



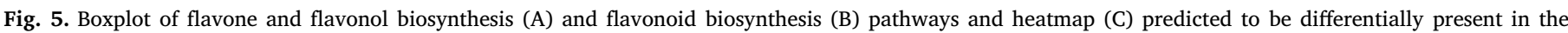
different experiments by using PICRUSt, visualized using STAMP.

\section{Conclusions}

The concentration of animal and PS metabolites (coprostanol, coprostanone, cholestanol, ethylcoprostanol and methylcoprostanone) was higher in experiments with microbiota of obese versus lean, suggesting a different microbial activity between these two population groups. In addition, the presence of PS-enrichment dose ( $2 \mathrm{~g} /$ day) there has been a modification of the cholesterol biotransformation route with a lower production of their main metabolites (coprostanol and coprostanone) fundamentally using lean population microbiota. Besides, PS-source ingredient and PS-mixture standard have been able to saturate the intestinal microbial metabolism of sitosterol for lean and obese population, which produces a decrease in the concentration of ethylcoprostanol (main sitosterol metabolite) and increase of ethylcoprostanone.

The total SCFA production was different between experiments with microbiota from lean and obese subjects, being higher when lean microbiota was used. This fact would support the hypothesis that the microbial profile of these population groups is different, which was corroborated by PCoA in QIIME (not shown). In presence of PS-enrichment dose, the production of acetate and butyrate increased significantly using mainly microbiota of lean population. Therefore, it could be confirmed that the supplementation of the diet with PS-enrichment dose would not modify the carbohydrates metabolic activity of the gut microbiota, and therefore SCFA continues to be produced. The enrichment of the culture medium with PS-source ingredient or PS- mixture standard increased the proportion of the genera belonging to the Firmicutes phylum. While in the control trials, the proportion of the genera that increase are those belonging to the Actinobacteria, Bacteroidetes and Firmicutes.

The present work is an in vitro study and although the obtained results showed be confirmed in human studies with daily intake of PS ( $2 \mathrm{~g}$ /day) over several weeks, the different fecal inocula used may lead to different effects on gut microbiota composition.

\section{Acknowledgements}

This study was part of a project funded by the Spanish Ministry of Economy and Competitiveness (AGL2012-39503-C02-01) (MINECOFEDER).

Maria Cuevas Tena holds a grant (BES-2013-062705) and a mobility aid for a research stay (EEBB-I-16-11870) from the Spanish Ministry of Economy and Competitiveness (MINECO).

The study was funded by the Centre for Healthy Eating \& Food Innovation (HEFI) of Maastricht University - campus Venlo. This research has been made possible with the support of the Dutch Province of Limburg.

\section{Conflict of interest}

The authors declare that they have no conflict of interest. 


\section{Ethics statements}

Our research did not include any human subjects and animal experiments.

\section{References}

Aguirre, M., Eck, A., Koenen, M. E., Savelkoul, P. H., Budding, A. E., \& Venema, K. (2015). Evaluation of an optimal preparation of human standardized fecal inocula for in vitro fermentation studies. Journal of Microbiological Methods, 117, 78-84.

Aguirre, M., Jonkers, D. M., Troost, F. J., Roeselers, G., \& Venema, K. (2014). In vitro characterization of the impact of different substrates on metabolite production, energy extraction and composition of gut microbiota from lean and obese subjects. PloS One, 9, e113864.

Arumugam, M., Raes, J., Pelletier, E., Le Paslier, D., Yamada, T., Mende, D. R., ... Bork, P. (2011). Enterotypes of the human gut microbiome. Nature, 473, 174-180.

Bäckhed, F., Ding, H., Wang, T., Hooper, L. V., Koh, G. Y., Nagy, A., ... Gordon, J. I. (2004). The gut microbiota as an environmental factor that regulates fat storage. Proceedings of the National Academy of Sciences of the United States of America, 101, 15718-15723.

Baumgartner, S., Mensink, R. P., De Smet, E., Konings, M., Fuentes, S., de Vos, W. M., \& Plat, J. (2017). Effects of plant stanol ester consumption on fasting plasma oxy (phyto) sterol concentrations as related to fecal microbiota characteristics. Journal of Steroid Biochemistry \& Molecular Biology, 169, 46-53.

Bernalier-Donadille, A. (2010). Fermentative metabolism by the human gut microbiota. Gastroenterologie Clinique et Biologique, 34, S16-S22.

Boulangé, C. L., Neves, A. L., Chilloux, J., Nicholson, J. K., \& Dumas, M. E. (2016). Impact of the gut microbiota on inflammation, obesity, and metabolic disease. Genome Medicine, 8, 42 .

Bray, G. A. (2004). Medical consequences of obesity. The Journal of Clinical Endocrinology \& Metabolism, 89, 2583-2589.

Caporaso, J. G., Kuczynski, J., Stombaugh, J., Bittinger, K., Bushman, F. D., Costello, E. K., ... Knight, R. (2010). QIIME allows analysis of high-throughput community sequencing data. Nature Methods, 7, 335-336.

Cohen, B. I., Raicht, R. F., \& Mosbach, E. H. (1974). Effect of dietary bile acids, cholesterol, and $\beta$-sitosterol upon formation of coprostanol and 7-dehydroxylation of bile acids by rat. Lipids, 9, 1024-1029.

Commission Regulation (EU) N ${ }^{\circ} 686 / 2014$ of 20 June 2014 amending Regulations (EC) $\mathrm{N}^{\circ} 983 / 2009$ and (EU) No 384/2010 as regards the conditions of use of certain health claims related to the lowering effect of plant sterols and plant stanols on blood LDLcholesterol.

Cuevas-Tena, M., Alegría, A., \& Lagarda, M. J. (2017). Determination of fecal sterols following a diet with and without plant sterols. Lipids, 52, 871-884.

Cuevas-Tena, M., Alegría, A., \& Lagarda, M. J. (2018). Relationship between dietary sterols and gut microbiota: A review. European Journal of Lipid Science and Technology. https://doi.org/10.1002/ejlt.201800054 (in press).

Cuevas-Tena, M., Bermúdez, J. D., Silvestre, R. A., Alegría, A., \& Lagarda, M. J. (2018). Impact of colonic fermentation on sterols after the intake of a plant sterol-enriched beverage: A randomized, double-blind crossover trial. Clinical Nutrition. https://doi. org/10.1016/j.clnu.2018.08.012 (in press).

Cuevas-Tena, M., del Pulgar, E. M. G., Benítez-Páez, A., Sanz, Y., Alegría, A., \& Lagarda, M. J. (2018). Plant sterols and human gut microbiota relationship: An in vitro colonic fermentation study. Journal of Functional Foods, 44, 322-329.

de Boer, J. F., Kuipers, F., \& Groen, A. K. (2018). Cholesterol transport revisited: A new turbo mechanism to drive cholesterol excretion. Trends in Endocrinology \& Metabolism, 29, 123-133.

Delzenne, N. M., Neyrinck, A. M., Bäckhed, F., \& Cani, P. D. (2011). Targeting gut microbiota in obesity: Effects of prebiotics and probiotics. Nature Reviews Endocrinology, 7,639.

van Faassen, A., Bol, J., van Dokkum, W., Pikaar, N. A., Ockhuizen, T., \& Hermus, R. J. (1987). Bile acids, neutral steroids, and bacteria in feces as affected by a mixed, a lacto-ovovegetarian, and a vegan diet. American Journal of Clinical Nutrition, 46, 962-967.

Frost, G., Sleeth, M. L., Sahuri-Arisoylu, M., Lizarbe, B., Cerdan, S., Brody, L., ... Bell, J. D. (2014). The short-chain fatty acid acetate reduces appetite via a central homeostatic mechanism. Nature Communications, 5, 3611.

García-Llatas, G., \& Rodríguez-Estrada, M. T. (2011). Current and new insights on phytosterol oxides in plant sterol-enriched food. Chemistry and Physics of Lipids, 164, $607-624$.

Gerard, P. (2016). Gut microbiota and obesity. Cellular and Molecular Life Sciences, 73 , 147-162.

Gibson, G. R., Probert, H. M., Van Loo, J., Rastall, R. A., \& Roberfroid, M. B. (2004), Dietary modulation of the human colonic microbiota: Updating the concept of prebiotics. Nutrition Research Reviews, 17, 259-275.

González-Larena, M., García-Llatas, G., Vidal, M. C., Sánchez-Siles, L. M., Barberá, R., \& Lagarda, M. J. (2011). Stability of plant sterols in ingredients used in functional foods. Journal of Agricultural and Food Chemistry, 59, 3624-3631.

Gylling, H., Plat, J., Turley, S., Ginsberg, H. N., Ellegård, L., Jessup, W., ... Silbernagel, G. (2014). Plant sterols and plant stanols in the management of dyslipidaemia and prevention of cardiovascular disease. Atherosclerosis, 232, 346-360.

Hamer, H. M., Jonkers, D. M. A. E., Venema, K., Vanhoutvin, S. A. L. W., Troost, F. J., \& Brummer, R. J. (2008). The role of butyrate on colonic function. Alimentary Pharmacology \& Therapeutics, 27, 104-119.

Hill, M. J., \& Aries, V. C. (1971). Faecal steroid composition and its relationship to cancer of the large bowel. The Journal of Pathology, 104, 129-139.

Kasai, C., Sugimoto, K., Moritani, I., Tanaka, J., Oya, Y., Inoue, H., ... Takase, K. (2015). Comparison of the gut microbiota composition between obese and non-obese individuals in a Japanese population, as analyzed by terminal restriction fragment length polymorphism and next-generation sequencing. BMC Gastroenterology, 15, 100 .

Keller, S., \& Jahreis, G. (2004). Determination of underivatised sterols and bile acid trimethyl silyl ether methyl esters by gas chromatography-mass spectrometry-single ion monitoring in faeces. Journal of Chromatography B, 813, 199-207.

Kimura, I., Inoue, D., Maeda, T., Hara, T., Ichimura, A., Miyauchi, S., ... Tsujimoto, G. (2011). Short-chain fatty acids and ketones directly regulate sympathetic nervous system via G protein-coupled receptor 41 (GPR41). Proceedings of the National Academy of Sciences, 108, 8030-8035.

Koenen, M. E., Rubio, J. M. C., Mueller, M., \& Venema, K. (2016). The effect of agave fructan products on the activity and composition of the microbiota determined in a dynamic in vitro model of the human proximal large intestine. Journal of Functional Foods, 22, 201-210.

Korpela, J. T. (1982). Capillary gas-liquid chromatography of faecal free and esterified neutral sterols. Scandinavian Journal of Clinical and Laboratory Investigation, 42, $529-534$.

Lagarda, M. J., García-Llatas, G., \& Farré, R. (2006). Analysis of phytosterols in foods. Journal of Pharmaceutical and Biomedical Analysis, 41, 1486-1496.

Langille, M. G., Zaneveld, J., Caporaso, J. G., McDonald, D., Knights, D., Reyes, J. A., .. Huttenhower, C. (2013). Predictive functional profiling of microbial communities using 16S rRNA marker gene sequences. Nature Biotechnology, 31, 814.

Lau, E., Carvalho, D., Pina-Vaz, C., Barbosa, J. A., \& Freitas, P. (2015). Beyond gut microbiota: Understanding obesity and type 2 diabetes. Hormones, 14, 358-369.

Lecomte, V., Kaakoush, N. O., Maloney, C. A., Raipuria, M., Huinao, K. D., Mitchell, H. M., \& Morris, M. J. (2015). Changes in gut microbiota in rats fed a high fat diet correlate with obesity-associated metabolic parameters. PloS One, 10, e0126931.

Leonel, A. J., \& Alvarez-Leite, J. I. (2012). Butyrate: Implications for intestinal function. Current Opinion in Clinical Nutrition \& Metabolic Care, 15, 474-479.

Ley, R. E., Bäckhed, F., Turnbaugh, P., Lozupone, C. A., Knight, R. D., \& Gordon, J. I. (2005). Obesity alters gut microbial ecology. Proceedings of the National Academy of Sciences of the United States of America, 102, 11070-11075.

Ley, R. E., Turnbaugh, P. J., Klein, S., \& Gordon, J. I. (2006). Microbial ecology: Human gut microbes associated with obesity. Nature, 444, 1022.

Lin, H. V., Frassetto, A., Kowalik, E. J., Jr, Nawrocki, A. R., Lu, M. M., Kosinski, J. R., .. Marsh, D. J. (2012). Butyrate and propionate protect against diet-induced obesity and regulate gut hormones via free fatty acid receptor 3 -independent mechanisms. PloS One, 7, e35240.

Maathuis, A., Hoffman, A., Evans, A., Sanders, L., \& Venema, K. (2009). The effect of the undigested fraction of maize products on the activity and composition of the microbiota determined in a dynamic in vitro model of the human proximal large intestine. Journal of the American College of Nutrition, 28, 657-666.

Mishra, A. K., Dubey, V., \& Ghosh, A. R. (2016). Obesity: An overview of possible role(s) of gut hormones, lipid sensing and gut microbiota. Metabolism, 65, 48-65.

Morrison, D. J., Mackay, W. G., Edwards, C. A., Preston, T., Dodson, B., \& Weaver, L. T. (2006). Butyrate production from oligofructose fermentation by the human faecal flora: What is the contribution of extracellular acetate and lactate? British Journal of Nutrition, 96, 570-577.

Mortensen, P. B., \& Clausen, M. R. (1996). Short-chain fatty acids in the human colon: Relation to gastrointestinal health and disease. Scandinavian Journal of Gastroenterology, 31, 132-148.

Parks, D. H., Tyson, G. W., Hugenholtz, P., \& Beiko, R. G. (2014). STAMP: Statistical analysis of taxonomic and functional profiles. Bioinformatics, 30, 3123-3124.

Perogambros, A., Papavassiliou, J., \& Legakis, N. J. (1982). Fecal neutral sterols in patients with colon cancer. Oncology, 39, 274-278.

Perrin, P., Pierre, F., Patry, Y., Champ, M., Berreur, M., Pradal, G., ... Menanteau, J. (2001). Only fibres promoting a stable butyrate producing colonic ecosystem decrease the rate of aberrant crypt foci in rats. Gut, 48, 53-61.

Portune, K. J., Benítez-Páez, A., Del Pulgar, E. M. G., Cerrudo, V., \& Sanz, Y. (2017). Gut microbiota, diet, and obesity-related disorders-The good, the bad, and the future challenges. Molecular Nutrition \& Food Research, 61, 1600252.

Reddy, B. S., \& Wynder, E. L. (1977). Metabolic epidemiology of colon cancer: Fecal bile acids and neutral sterols in colon cancer patients and patients with adenomatous polyps. Cancer, 39, 2533-2539.

Segata, N., Izard, J., Waldron, L., Gevers, D., Miropolsky, L., Garrett, W. S., \& Huttenhower, C. (2011). Metagenomic biomarker discovery and explanation. Genome Biology, 12, R60.

Stellaard, F., \& Lütjohann, D. (2015). Fractional cholesterol absorption measurements in humans: Determinants of the blood-based dual stable isotope tracer technique. Journal of Clinical Lipidology, 9, 14-25.

Turnbaugh, P. J., Ley, R. E., Mahowald, M. A., Magrini, V., Mardis, E. R., \& Gordon, J. I. (2006). An obesity-associated gut microbiome with increased capacity for energy harvest. Nature, 444, 1027-1031.

Turnbaugh, P. J., Ridaura, V. K., Faith, J. J., Rey, F. E., Knight, R., \& Gordon, J. I. (2009). The effect of diet on the human gut microbiome: A metagenomic analysis in humanized gnotobiotic mice. Science Translational Medicine, 1, 6 ra14.

Venema, K., Vermunt, S. H., \& Brink, E. J. (2005). D-Tagatose increases butyrate production by the colonic microbiota in healthy men and women. Microbial Ecology in Health and Disease, 17, 47-57.

Weststrate, J. A., Ayesh, R., Bauer-Plank, C., \& Drewitt, P. N. (1999). Safety evaluation of phytosterol esters. Part 4. Faecal concentrations of bile acids and neutral sterols in healthy normolipidaemic volunteers consuming a controlled diet either with or without a phytosterol ester-enriched margarine. Food and Chemical Toxicology, 37, 
1063-1071.

WHO (2018). Obesity and overweight. Fact sheet $n^{\circ} 311$. Available: < http://www.who. int/news-room/fact-sheets/detail/obesity-and-overweight > Accessed in September 2018.

Wilkins, T. D., \& Hackman, A. S. (1974). Two patterns of neutral steroid conversion in the feces of normal North Americans. Cancer Research, 34, 2250-2254.

Wong, A. (2014). Chemical and microbiological considerations of phytosterols and their relative efficacies in functional foods for the lowering of serum cholesterol levels in humans: A review. Journal of Functional Foods, 6, 60-72. 